\title{
Analysis of the Contact Stresses in Curvic Couplings of Gas Turbine in a Blade-Off Event
}

\author{
X.-J. Jiang, Y.-Y. Zhang, and S.-X. Yuan \\ Xi'an Jiaotong University, Xi'an, Shaanxi, People's Republic of China
}

УДК 539.4

\section{Расчет контактных напряжений в криволинейных сочленениях дисков газовой турбины в случае отрыва лопатки}

\begin{abstract}
Кс.-Ж. Жианг, Ю.-Ю. Жанг, С.-Кс. Юань
Сианьский транспортный университет, Сиань, Шэньси, КНР

С помощью трехмерной конечноэлементной модели исследовано распределение контактных напряжений в криволинейных сочленениях высоконагруженной газовой турбины в условиях, соответствующих случаю отрыва лопатки. Для разных положений оторвавшихся лопаток на диске каждой ступени распределение контактных напряжений в криволинейных сочленениях в случае приложения усилий, соответствуюших отрыву лопатки, различается. При этом точка приложения и величина усилия, а также распределение усилий затяжки болтов крепления оказывают существенное влияние на распределение контактных напряжений. Кроме того, характер изменения контактных напряжений как с одной, так и с другой стороны "зуба" сочленения при наличии крутящего момента различается из-за усилия, обусловленного отрывом лопатки. Помимо нормальной центробежной силь возникает неуравновешенная изгибающая сила. Показано, что жесткость сочленяемой части ротора между ториами компрессора и турбины, определяемая жесткостью его сечения, оказывает влияние на распределение контактных напряжений в криволинейных сочленениях. Выполнен расчет жесткости для каждого из таких сочленений.
\end{abstract}

Ключевые слова: криволинейное сочленение, трехмерный конечноэлементный метод, отрыв лопатки, контактное напряжение.

Introduction. The curvic couplings are the important components of a gas turbine widely used in the aero-engine and electric power generation industry to drive rotating equipment and safely transfer high torque without relying on friction between the contacting surfaces of the curvic couplings. Its advantages such as reliable location, precise centring ability, excellent structural stability, strong load bearing ability definitely make the curvic couplings used more and more widely in the high speed rotating machine for torque transmission.

The stress of the bolt with the curvic coupling in the event of a blade release in the three-dimentional finite element model was analyzed by Richardson et al. [1] for an improved design of the curvic coupling. The centre bolted rotor with the curvic couplings of an aero-engine was studied by Zeyong et al. [2] and Baian et al. [3]. However the statuses and stresses of the curvic couplings were never involved by them. Bannister [4] carried some work to determine the equivalent flexural stiffness of a curvic coupling in order to analyze the rotor character in 
dynamics. Pisani and Rencis [5] compared the results from the finite and boundary element methods of a single tooth non-contact model in simple two and three dimensions, then analyzed the nominal hoop stress with the corresponding stress concentration factor in the curvic coupling. The photoelastic experimental technique was employed by Richardson et al. [6] for a validation of the three-dimensional finite element contact method in the curvic coupling. The stress distribution and contact behavior of the curvic couplings in three-dimensional finite element model of a heavy duty gas turbine with the spindle bolted rotor were analyzed by Yuan et al. [7] during the load cases of preload, warm-up, speed-up, and running of the rotor.

The aim of this paper is to discribe the contact pressure of the curvic couplings in the event of a blade release in the turbine end of a heavy duty gas turbine in the three-dimentional finite element model. The curvic coupling should have the capacity to hold the load given to it under this load case, otherwise if the curvic coupling fails to work regularly, the whole disc maybe free to depart from the rotor and then penetrate the turbine. Therefore it is very important for the curvic coupling design to avoid this case. The contact surface of the curvic couplings in the three-dimentional finite element model should be defined. The load cases applied to the finite element model were the initial bolt preload, the blade-off centrifugal load and then the torque load. The blade-off centrifugal load means the extreme event of a blade release. The analysis results of the stresses of the curvic couplings have been carried out to present the influence of the blade-off centrifugal load and the torque load.

1. Description of Curvic Couplings. There are four disks in gas turbine be assembled via curvic coupling interface with 12 high strength spindle bolts for increased clamp load and torque capacity. The tooth number of the curvic coupling in one side of the disk is 180 . The curvic coupling design allows for accurate, light, compact, and self-contained connection in which the curvic teeth serve as centering and driving devices. The geometry parameters of the curvic coupling in the heavy duty gas turbine are critical for the stress analysis of the curvic couplings and had been given by Yuan et al. [7]. The skeleton of a curvic coupling is very complex, therefore a lot of parameters needed to be defined to describe the curvic geometry. The contact of the curvic coupling is hundred-percent owing to the special manufacture method. The two sides of coupling half are machined by external tool and internal tool respectively. This conducts to a different geometry on either side of the coupling.

2. Finite Element Modeling and Calculation Procedures. There are currently no analytical solutions available, which deal with the blade-off load case in every stage disc. Further, analytical solutions generally deal with the blade-off load case only in a fixed blade-off position [1] but not the positions in every stage disc as expressed in this paper. Therefore to determine the state of contact pressure about the curvic surface in the disc during the applied load cases, a three-dimensional finite element model, as illustrated in Fig. 1, should be adopted in the present study and the stress analysis of the rotor was carried out. A commercial software ANSYS [8] with three-dimensional, eight-noded brick elements is employed in this study. The refinement of the mesh on the curvic couplings is crucial to capture the correct stress magnitudes and its distribution. For this, a convergence study had been 
developed by Yuan et al. [7] to determine the mesh refinement which was performed based on the analytical solution. The mating surfaces of the external and internal curvic halves have matching meshes while the Lagrange multiplier method is used for the interaction between the surfaces. A large amount of sliding could be allowed in this analysis, but requires much more complex calculations, particularly for two three-dimensional deformable bodies in contact. Therefore all contact analyses in this paper have used the small sliding option. Some geometry has to be simplified due to its exceedingly complex for the current problems, especially the fillet radius and the screw thread of the spindle bolts and nuts. However it has been proved that this simplification is valid and does not influence the analytical results for the contact pressure of the curvic couplings, so that the behaviour of the coupling under the every load case can be accurately captured. The material properties for obtaining the analytical results in the current investigation had been given elsewhere [7].

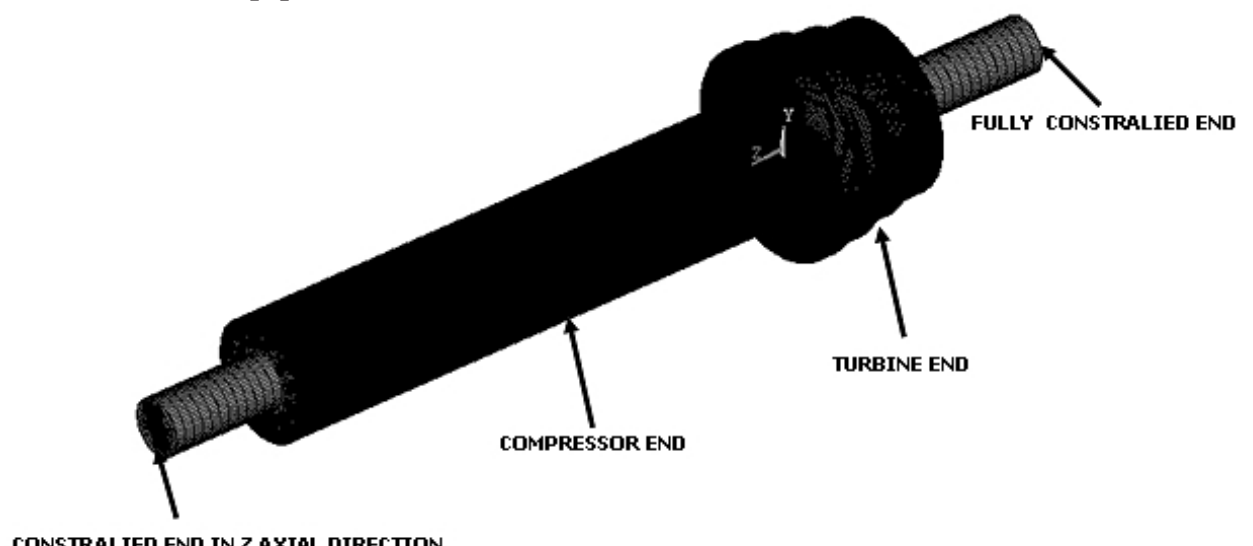

CONSTRALIED END IN Z AXIAL DIRECTION

Fig. 1. Global finite element model.

Previous study had shown that a cyclic symmetry finite element model simulating one 15-tooth segment of the coupling could be used for cyclically symmetric loading conditions, such as clamp and torque load. However, with the induction of non-symmetric loading, i.e., the blade-off load with torque, it becomes necessary to model the full 180 -tooth $360^{\circ}$ geometry. Because the need for accurate stress-strain predictions would significantly increase the demand on mesh refinement at the cost of computational resources, the 180-tooth model is limited to a coarse mesh in this paper.

The initial bolt preload, the blade-off centrifugal load and the torque load are consecutively applied to the finite element model. The shortening distance method between the two nuts is applied to simulate the bolt preload, its value is $5.6 \mathrm{~mm}$ as discussed by [7], which produces a bolt force about $200 \mathrm{kN}$. The torque load is applied as shown in Fig. 2. In this article the analysis in the finite element model with torque load is based on the design value of the power at every stage disc at the outer surface of the disc. The torque load value could be calculated as follows:

$$
T=9550 \frac{P}{n}
$$


where $T$ is the input torque load on each stage disc, $P$ is the input power on each stage disc, and $n$ is the rotating speed of rotor. The input torque load on each stage disc is listed in Table 1. It should be noted that the power produced by turbine end should be shared by the compressor end in the proportion of $46 \%$ to keep that part working. Therefore, the input torque load should also be applied on the compressor end as shown in Table 1.

$\mathrm{T}$ a b 1 e 1

Input Parameters in Turbine End Discs for Calculation

\begin{tabular}{|c|c|c|c||}
\hline \multicolumn{3}{|c|}{ Input data } \\
\hline Stage disc & $\begin{array}{c}\text { Mass of single blade } \\
(\mathrm{kg})\end{array}$ & Total number of blade & $\begin{array}{c}\text { Input power } \\
(\mathrm{kW})\end{array}$ \\
\hline 1 & 7.05 & 96 & 20.52 \\
2 & 9.29 & 87 & 20.97 \\
3 & 9.12 & 112 & 23.08 \\
4 & 14.91 & 100 & 19.65 \\
Compressor end & \multicolumn{2}{|c|}{ Input data for calculation } & 38.81 \\
\hline \multirow{2}{*}{ Stage disc } & Centrifugal force & Over degree of single & Input torque \\
& of single blade (kN) & blade possesses $\varphi($ deg $)$ & load $(\mathrm{kN} \cdot \mathrm{m})$ \\
\hline 1 & 785.99 & 3.75 & 34.74 \\
2 & 1023.94 & 4.14 & 35.86 \\
3 & 985.95 & 3.21 & 40.23 \\
4 & 1589.29 & 3.60 & 34.74 \\
\hline
\end{tabular}

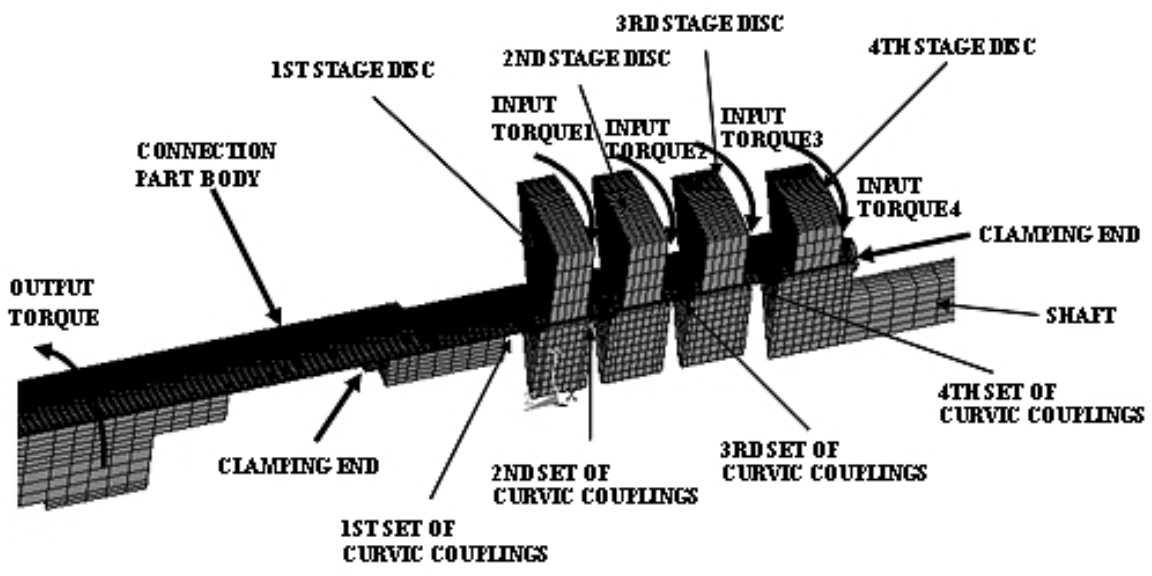

Fig. 2. View of a $30^{\circ}$ section of the curvic couplings model.

One of the most important uncertainties in modeling of the stress analysis is the blade-off load case. The blade number is approximately 100 in each stage disc, it is impossible to consider each blade-off case in every position. Therefore two typical positions of blade release in each stage disc have been analyzed in this 
paper, as shown in Fig. 3. One of the blade-off positions is at the upward side of one spindle bolt, another one is located bang in the middle of two spindle bolts along the circumference of disc. Actually, the blade-off centrifugal load can be seen as an equivalent bending force applied at the opposite side of the blade-off position with the magnitude of a blade centrifugal force. Therefore these two typical positions of blade release in one stage disc can help to survey the behavior of the contact surface of the curvic couplings with the different stiffness due to the spindle bolts under the different equivalent bending forces conditions.

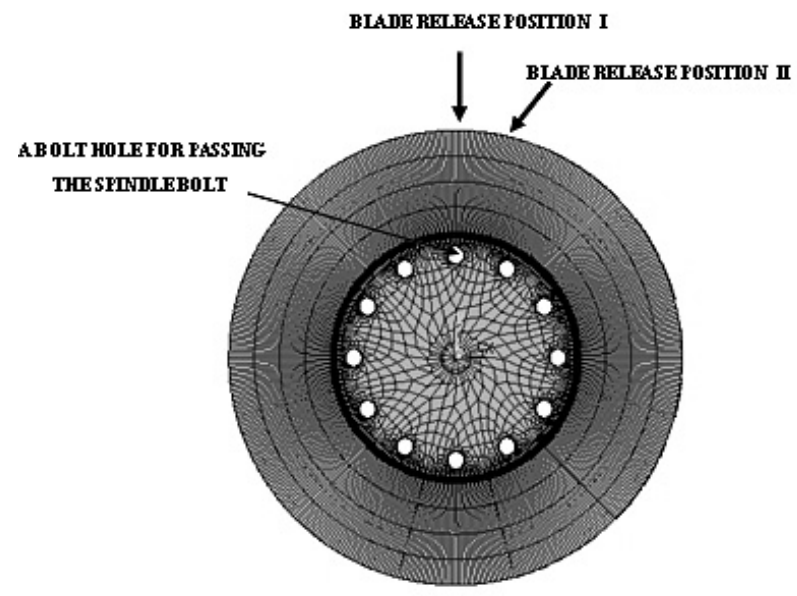

Fig. 3. View of the position in the disc where the blade releases.

The torque load is applied at the nodes attached to the outer surface in the circumference direction of the disc in the global cylindrical coordinate. These nodes could be considered remote enough from the interest region of the curvic couplings. Therefore the influence in the contact pressure analysis is very small with this method that thus can be considered valid. It is noted that the input torque at the turbine end is different due to the different power generated in each stage disc. However the total of the input torque at the turbine end is consistently equal to the output torque at the compressor end, just as the feature of power in the gas turbine.

The blade centrifugal load is applied in the same method as the mentioned applied torque load above. The rotating speed of this rotor according to the design parameters is $3000 \mathrm{rpm}$ under the regular work condition of the heavy duty gas turbine. Therefore the blade centrifugal force can be calculated according to the rotating speed of the rotor and the mass and centroid of the blade, written as

$$
F=m \omega^{2} r
$$

where $F$ means the blade centrifugal force, $m$ is the mass of one blade, $\omega$ is the angular velocity of rotor which is corresponding to the rotating speed of the rotor $n$, and $r$ is the distance between the center point of disc and the mass center point of blade. In these analyses, the mass center point of blade is assumed at the outer surface of the disc for simplification. 
As the blade is health and sound, all of blade centrifugal forces enforced on each stage disc are applied on the outer surface in the circumference direction of the disc evenly in the radial direction. However if the rotor is working under the condition of one blade release, the loading area should be changed. This means that the blade centrifugal load would be applied on the same surface of the disc except for the located area over some degree according to the blade-off positioning. The degree of one blade possesses is derived from the blade number in each stage disc, which could be written as

$$
\varphi=\frac{360}{n_{b}}
$$

which $\varphi$ is the degree of one blade possesses and $n_{b}$ is the total number of blade in one stage disc. These data details are shown in Table 1.

To analyze successfully the influence of the different load cases on the curvic couplings, a parameter should be selected to carry out. Because of the role of the torque load, the tooth should bear the load more in one side and less in another side. Therefore the parameter of the mean contact pressure of the curvic contact surface is thought as most appropriate one for the current problem, the associated value get by the elements of the tooth contact area. In this approach, the mean contact pressure is computed on all planes at all points in the contact region. Of course, the influence of the clamp load and the blade-off load cases on the contact pressure of all curvic couplings could be depicted well by this parameter. In other words, this parameter is effective in characterizing the curvic contact behavior under the mentioned load condition above. The tooth numbering convention in a clockwise order as well as the left and the right side surfaces of the teeth are shown as polar plots in Fig. 4. It should be mentioned that only the contact pressure of one set of curvic half in each curvic couplings set is considered due to its completely same characters.

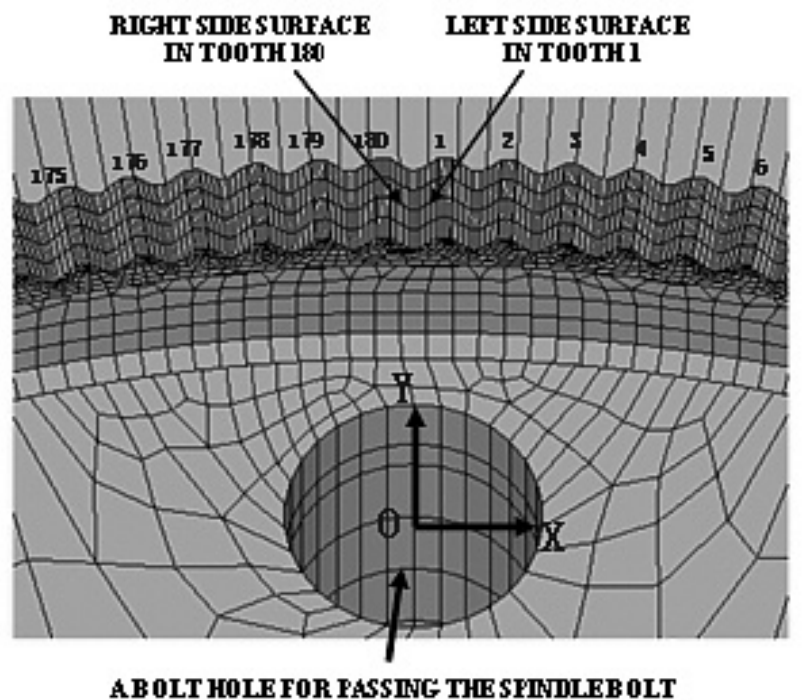

Fig. 4. Close-up view of the bottom half of a disc submodel for curvic numbering. 


\section{Numerical Results.}

\subsection{Mean Contact Pressure Characteristics of the Curvic Couplings under} Normal Load Condition. There are several possible contact pressure characteristics on the curvic couplings when the normal sequence loads are applied. The first step involved the application of the clamp load at the turbine end of the heavy duty gas turbine. After the application of the clamp load, a corresponding contact pressure develops along the tooth interface due to the compression between the two contacting bodies. The mean contact pressure of all curvic couplings at each stage disc due to the clamp load case is shown in Fig. 5. There is not apparent difference in the contact pressure in each curvic couplings set, which is about $170 \mathrm{MPa}$. This mean contact pressure shows a symmetric distribution on the right and the left sides of one tooth. It reflects the equal deformation on the right and the left sides of the contact surface of opposite sign, which is shown to maintain equilibrium. There are twelve small cycle stress distributions in wavy form could be found in overall distribution. This each small cycle stress distribution could be thought as corresponding to the function of the spindle bolt. It could be easy to understand that the mean contact pressure is higher at the tooth closer to the bolt because of the role of the bolt clamping. However, Fig. 5a shows a different character from the other pairs in the stresses magnitude, this cause can be sought from the construction of the connector with the curvic couplings. From Fig. 2, we can see that the connection body in the 1st set of curvic couplings is longer than those bodies in other sets of curvic couplings, which results in the feeble stiffness in the 1 st set of curvic couplings in preload case.

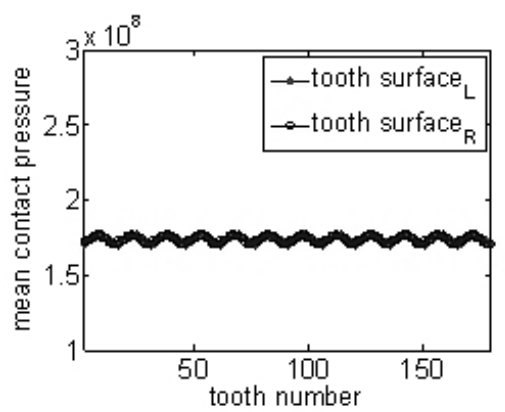

a

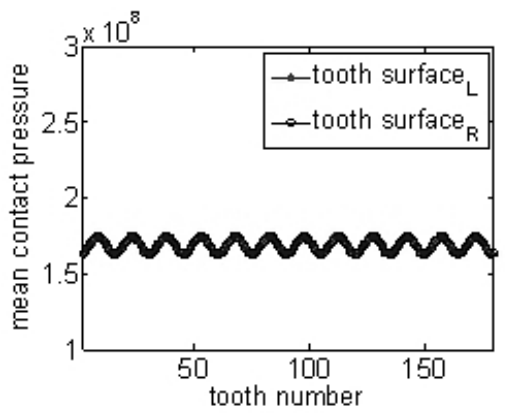

c

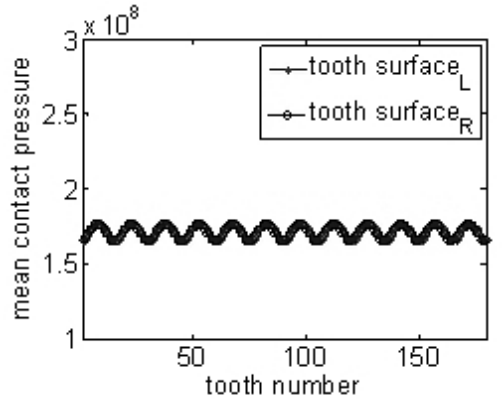

$\mathrm{b}$

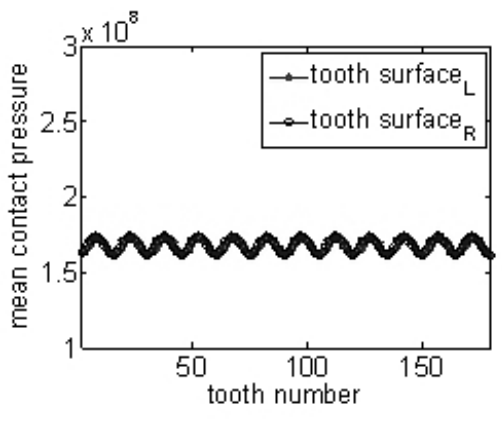

d

Fig. 5. Mean contact stresses (in $\mathrm{Pa}$ ) under preload condition: (a) in the 1 st set of the curvic couplings; (b) in the 2nd set of the curvic couplings; (c) in the 3rd set of the curvic couplings; (d) in the 4 th set of the curvic couplings. 
As the blade centrifugal load is applied further, the mean contact pressure will change in magnitude values. Although a large part of characteristics of mean contact pressure are similar to those in first step load, it present opposite contact stress distribution trend in that lower value at the tooth closer to the bolt. The centrifugal load of the discs and blades make the contact stress distribution more even along the radial direction, and then the phenomenon of the stress concentration would be weakened. Simultaneously the stronger equivalent stress seems to be closer to the tooth root from the finite element analysis results which are unlike those with the clamp load only. This is the reason why the mean contact pressure at the tooth closer to the bolt is lower under the further blade centrifugal load condition than under the clamp load condition only.

The mean contact pressure is different in each set of curvic couplings surfaces. One reason is that the centrifugal load of the disc and all blades is different in each stage disc, therefore the stretching function for each set of curvic couplings is different in radial direction. Another reason is owing to the spindle bolts construction. The spindle bolts is initially designed with some steps for decreasing the stress concentration under the centrifugal load condition at its contact location with the associated disc. The distance between every pair of the steps is different which leads to the difference stiffness in every segment body of the bolt. Therefore, the different role of every segment body of the bolt is reflected on the contact interface of the curvic couplings after the centrifugal load is applied. However, this little distinctness in contact pressure of each set of curvic couplings has no influence obviously on the properties of the rotor in mechanics and dynamics.

The power is transformed into the torque force, and then is impressed upon all stage discs. The curvic couplings have played a very important role in torque transmission. Therefore the curvic contact pressure is necessary to be analyzed under the torque load condition with a blade release. The analysis results show that the first set of curvic couplings which is closest to the compressor end share the most responsibility for output power, because the stress difference value in this set of curvic couplings is the largest in all sets of curvic couplings. Note that the left side surface contact pressure is bigger than the results by previous step load as compared with the right side surface contact pressure in lower value. It is because the left side contact surface is compressed by two contact bodies for bearing the torque load and another side contact surface is relaxed under the same load condition. It could be concluded that the closer the curvic couplings get to output power end, the more the couplings bear the output load.

\subsection{Mean Contact Pressure Characteristics of the Curvic Couplings under}

Blade-Off Load Condition. As mentioned earlier, an investigation of the threedimensional finite element model conducted under a blade-off load case should be analyzed to obtain the contact pressure of the curvic couplings to understand the influence of the blade-off centrifugal load on the behavior of the curvic couplings.

To demonstrate these different types of the contact pressure of the curvic couplings during a blade-off load case with different positions, several blade-off position cases are investigated. These load conditions are summarized in following. The blade-off centrifugal load is applied on the outer surface in the circumference direction of the discs except for the located area over some degree according to the blade-off position I at the upward side of one spindle bolt in first stage disc in first 
load case (I). Magnitude of blade-off centrifugal force, used in this analysis, is obtained by the design data of the blade in the first stage disc. The second case (II) is similar to case I, but the position of blade release is changed to the bang in the middle of two spindle bolts along the circumference of the disc shown as Fig. 3, so that the influence of the stiffness due to the spindle bolts under the equivalent bending force condition in this case is present. To demonstrate further the effect of blade-off position I at second stage disc relative to that at the first stage disc, a third case (III) is considered. It is similar to case I except that the stage of the disc is switched to the second one. The fourth case (IV) still is limited to the second stage disc, which is similar to that in case III, but the blade-off load is applied to the position II. The fifth case (V) and sixth case (VI) consider the effect of applying blade-off centrifugal load at position I and II respectively in the third stage disc. The seventh case (VII) and eighth case (VIII) use the same load as those in case $\mathrm{V}$ and VI in locating position, but they are applied in the forth stage disc. To highlight their curvic couplings characteristics, these cases are discussed in detail.

Case I: The mean contact pressure distribution of all sets of curvic couplings under the blade-off centrifugal load condition is shown in Fig. 6 for this case. The mean contact pressure distribution in whole with tooth number order is shown a concave profile. It can be realized that the contact surface of the curvic couplings has been getting slack in the opposite side of the blade-off location, and in contrary tight in the identical side of that location. In other words, the function of the clamp load of the bolts is weakened in that opposite side location, and in comparison strengthened in the same side due to the equivalent bending force in that the role of the unsymmetrical blade-off centrifugal load. Therefore, the mean contact pressure of the curvic couplings is shown decreasing in that opposite side location and increasing in that same side. Hence, the unsymmetrical mean contact pressure distribution has been developed in whole in each set of curvic couplings.

A slight shift and asymmetry in the mean contact pressure distribution in two sides of contact surface of all teeth in one set of the curvic couplings can be seen (Fig. 6b-d) which are anti-symmetric each other in the left and right sides of the contact surfaces of the teeth due to the applied blade-off centrifugal load. On this phenomenon, the major factor is owing to the feeble stiffness in the connection part of the rotor between the compressor end and the turbine end, as shown in Fig. 2. Therefore, there is only a very slight influence can be observed on the deformation of the first set of the curvic couplings in roundness at the side close to that connection part, as shown in Fig. 6a. However, the sets of the curvic couplings at another side aback to that part come into being a relative big deformation in roundness due to the holding strong stiffness of the shaft. The mentioned factor above eventually contributes to the anti-symmetric stress distribution on the mean contact pressure of the curvic couplings close to the shaft side.

Case II: The influence on the stiffness of the rotor with the spindle bolts due to the equivalent bending force should be accounted in this analysis, and had been ignored in the previous study [1] where the blade-off load is modeled in a fixed position. From the analysis results, it is noted that the mean contact pressure distribution in whole with tooth number order shown a concave profile, and the anti-symmetric stress distribution each other in the left and right sides of the contact surfaces of the teeth due to the applied blade-off centrifugal load. It should 
be mentioned that the start point to count the tooth is changed to the No. 15 tooth in case I, which can be considered corresponding to the position of the blade release in radial direction. All these characteristics are similar to those in case I. The major difference between cases II and I is the magnitude of contact stress difference value which observed apparently increases as compared with the analysis results of case I. Therefore the conclusion can be drawn that the stiffness of the rotor decreases in this case compared to last case, which is not difficult to be understood that this phenomenon should be related to the construction of the spindle bolts rotor.

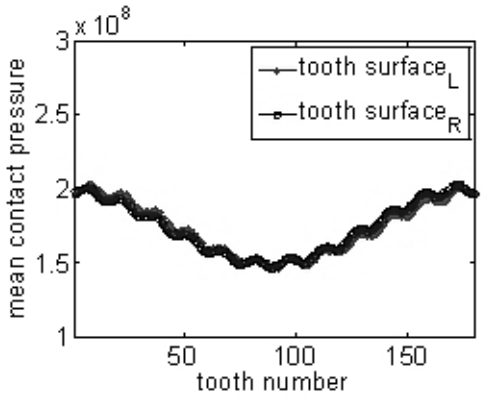

a

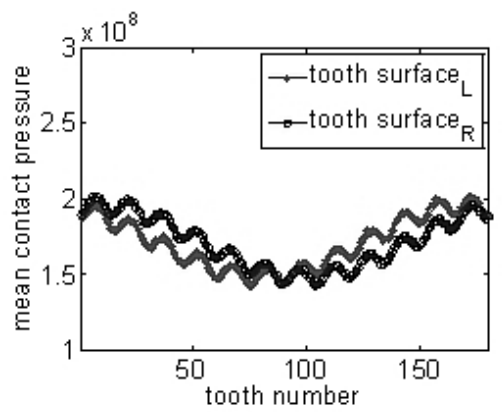

$\mathrm{C}$

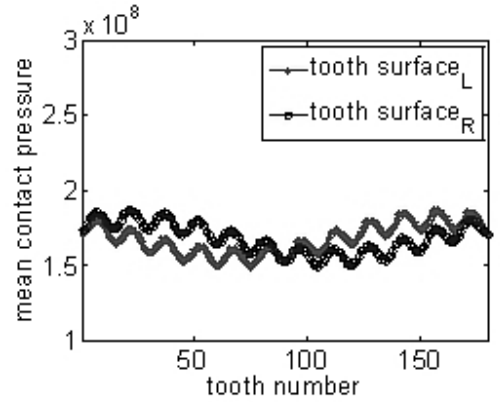

b

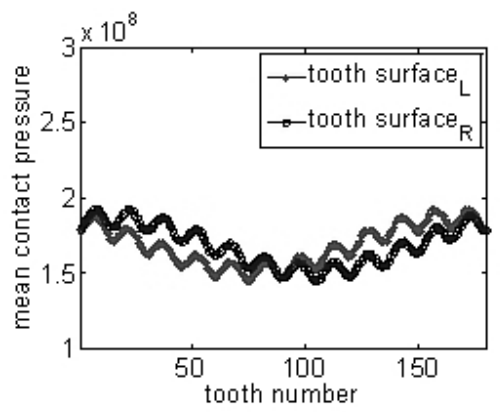

d

Fig. 6. Mean contact stresses (in Pa) of the curvic couplings under a blade-off load condition at the first stage disc: (a) in the 1st set of the curvic couplings; (b) in the 2nd set of the curvic couplings; (c) in the 3rd set of the curvic couplings; (d) in the 4th set of the curvic couplings.

Case III: To show that the mean contact pressure of the curvic couplings depends on the position of blade release to that of stage disc, this case is considered. Loading conditions are the same as those in case I except that the position of applied blade-off load is located at position I of the second stage disc. According to analysis results, the mean contact pressure distributions along the second set of curvic couplings have similar characteristics to those in case I, except for the magnitude of stress difference value. The reason why the magnitude of contact stress difference value is different has been given above. However, the format of the stress anti-symmetric distribution in the second set of curvic couplings has disappeared in case III instead of the format similar to the distribution in the first set of the curvic couplings. Hence it can be concluded that the feeble stiffness in the connection part plays a critical role in this stress distribution change. 
Case IV: In this case, the blade-off centrifugal load is applied in the second stage disc at position II. From the analysis results, the stress distributions have similar characteristics corresponding to those in case III, except for the small increment in the magnitude of stress difference value, hence these are not shown. Therefore, the explanation that the stiffness of the rotor decreases in case II is still effective in this case.

Case V: The purpose of this case is to show that the blade-off centrifugal load applied in the third stage disc at position I causes how the mean contact pressure distribution of this corresponding set of curvic couplings changes. As expected, the contact pressure distributions are similar to those of case III correspondingly, and the distribution in the third set of the curvic couplings is symmetric in the left and right sides of the contact surfaces of the teeth in distinction to that in case III. The change in contact pressure distribution is also due to the feeble stiffness in the connection part of the rotor which is similar to the contact stress distribution in the second and third sets of curvic couplings.

Case VI: The concave profile and anti-symmetric stress distribution occur under the blade-off centrifugal load in third stage disc at position II condition in this case. Similar phenomenon has been seen in case V except for the little increase in the magnitude of contact stress difference value that had been explained earlier.

Case VII: Under the blade-off centrifugal load applied in the fourth stage disc at position I condition, the stress distribution present symmetric character uniformly. Though the magnitude of contact stress difference value is different compared to the earlier study due to the different blade-off centrifugal load and the changing stiffness in rotor, the influence of the feeble stiffness in the connection part of the rotor on the distribution of the curvic contact pressure is obviously observed from the analysis results, just the same as the mentioned study above.

Case VIII: This case is no shown due to its similar analysis results with case VII except for the magnitude of stress difference value. The cause in this phenomenon had been interpreted in case II, case IV, and case VII. Therefore there is no explanation more in this case.

In summary, these cases, I-VIII, are analyzed to develop an understanding of contact behavior of the sets of curvic couplings under a blade-off load condition. Above results show that the mean contact pressure distributions characteristics of the sets of curvic couplings under a blade-off load condition depend on the position and magnitude of the applied blade-off load, the distribution of the spindle bolts, and the stiffness of the bodies connected to the turbine discs (i.e., the connection part of the rotor between the compressor end and the turbine end). This is markedly in contrast to the stress distribution mode under normal blade centrifugal load condition, which is symmetric along the teeth in numbering.

3.3. Mean Contact Pressure Characteristics of the Curvic Couplings under Final Torque Load Condition. Continuing the blade-off load, it is interested that how the stress distribution change after the torque load is applied. According to the earlier analysis under the normal load condition, the torque load make the magnitude of contact pressure difference value on the left and right sides of the teeth change, it means the left side surface contact pressure increasing and the right side surface contact pressure decreasing for bearing the torque force. In this analysis, a torque load has been applied following the blade-off load in case I in 
the three-dimensional finite element model. From the results shown in Fig. 7, it can be concluded that the application of the torque load has a significant effect on the stress distribution of the curvic couplings. It keeps similar characters with the stress distribution not only in normal load for increasing the stress value on the left side and decreasing the one on the right side of one tooth, but also in the torque load following the blade-off load for the anti-symmetric character.

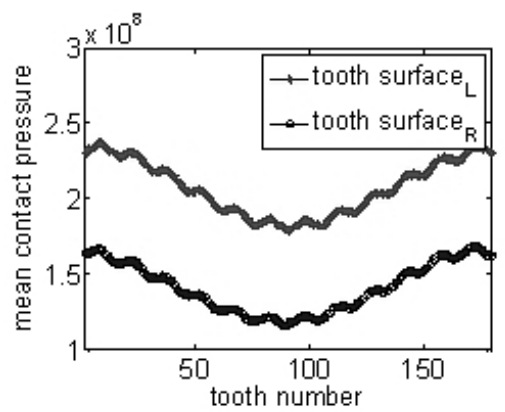

a

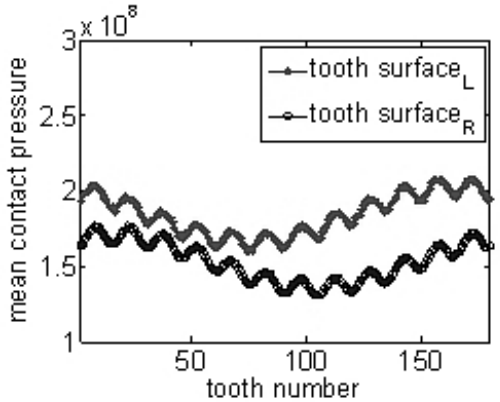

$\mathrm{C}$

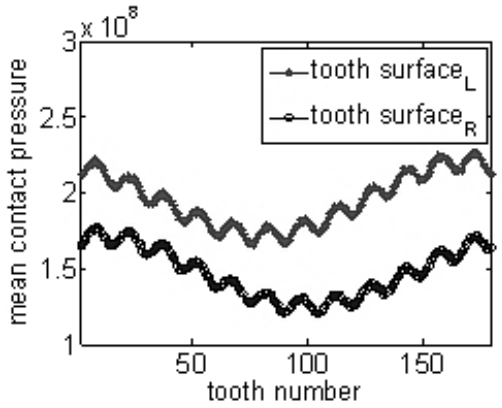

$\mathrm{b}$

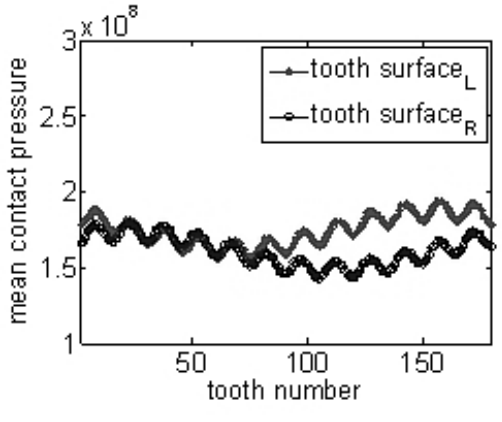

d

Fig. 7. Mean contact stresses (in $\mathrm{Pa}$ ) of the curvic couplings under a torque load condition following the blade-off load case at the first stage disc: (a) in the 1st set of the curvic couplings; (b) in the 2nd set of the curvic couplings; (c) in the 3rd set of the curvic couplings; (d) in the 4th set of the curvic couplings.

The results of all the analysis in the torque load following the blade-off load in all cases illustrate that the same evolution character in that stress distribution with the torque load following the case I, therefore these are not shown. It can be predicted that these stress distributions due to its disharmony may cause some problems of the rotor in mechanics or dynamics.

3.4. Effect of the Stiffness of the Connection Part in Blade-Off Load. In previous work [1], it had been shown that the geometrical change had important effect in the stress distribution of the component in the rotor (i.e., the bolts). From the analysis previously in this paper, the stiffness in the connection part of the rotor between the compressor end and the turbine end associated with its section thickness is crucial in deciding the contact stress distribution on the sets of the curvic couplings close to that part. Any variation in its thickness would obviously have an effect on the stress distribution caused by the blade-off load on one stage disc. A finite element analysis has been carried out to investigate the possible effect of changing the section thickness of this particular variation. 


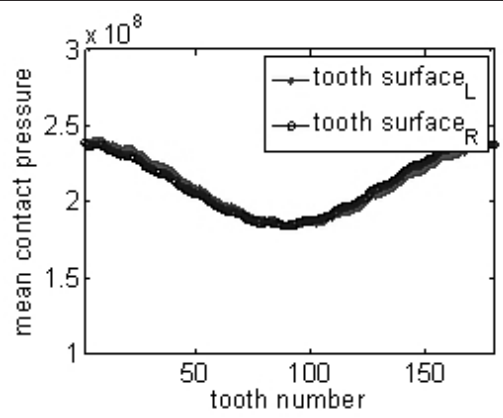

a

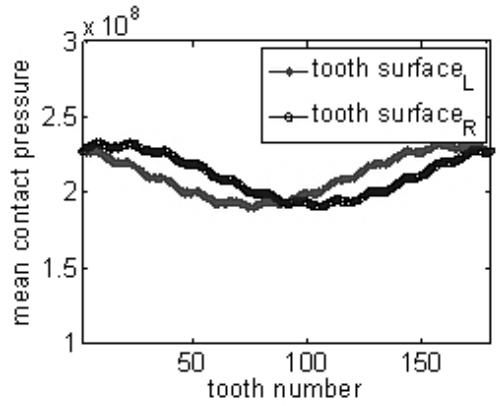

c

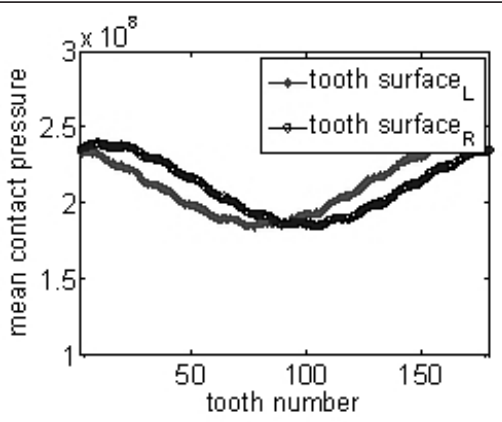

b

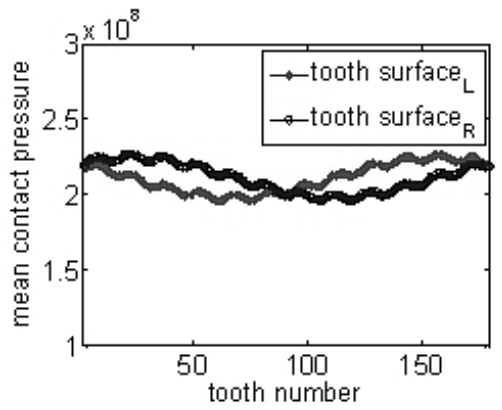

d

Fig. 8. Mean contact stresses (in Pa) of the curvic couplings under a blade-off load condition at the first stage disc as the thickness of the connection part section is increased: (a) in the 1st set of the curvic couplings; (b) in the 2 nd set of the curvic couplings; (c) in the 3 rd set of the curvic couplings; (d) in the 4th set of the curvic couplings.

One of main design objectives in the gas turbine industry is to reduce the weight on the premise of guaranteeing the strength of this rotor. Though increment in the thickness of the connection part section is favorable to increase the stiffness and stability of the running rotor, it fails to agree with the prime principle in designing the gas turbine. Therefore, analysis is presented that has the section thickness increasing only one time comparing with the original thickness under the blade-off load at position I condition. From Fig. 8 compared with Fig. 6, the twelve small-cycle contact stress oscillation of the curvic couplings is suppressed obviously due to the increasing thickness in this connection part section. It can be concluded that the increasing thickness in this connection part section has a significant influence on the stress distribution of the curvic couplings and then on the behavior within the curvic rotor. It seems that the tactic to increase the thickness in this connection part section is very benefit for improving the stability of the gas turbine rotor, but Fig. 8 still shows a large increasing value in whole stress distribution as compared with the results in case I. In the opposite situation, the case of decreasing the thickness of the connection part section to half of the original thickness is also analyzed with the same load condition as the mentioned above. From the analysis results, it could be found that there appears to be no notable effect on the contact stress distributions in the curvic couplings.

Conclusions. A full 180 -tooth, $360^{\circ}$ geometry three-dimensional finite element model of the curvic rotor has been established for examining the effect of a 
blade-off centrifugal load and then a torque load on the mean contact pressure distribution of the sets of curvic couplings. Though there is no available technology in finite element has the ability to get a complete analysis in this model for considering the every blade release position in all stage discs, the selected typical blade-off position method likewise sufficiently analyzes the effect on a blade-off load case. Based on the present study, the following observations are made.

1. A torque load following the normal centrifugal load has been considered to obtain the mean contact pressure distribution of the sets of curvic couplings for providing a criterion to judge whether the contact pressure distribution of those curvic couplings under a blade-off centrifugal load event can be thought of the unreasonable results.

2. The mean contact pressure distributions characteristics of the sets of curvic couplings under a blade-off load condition not only depend on the position and magnitude of the applied blade-off load but also on the distribution of the spindle bolts as well as the stiffness of the connection part body. The blade-off load causes a equivalent bending force in the opposite direction of the blade release position. Because of the equivalent bending force, the asymmetric and anti-symmetric contact pressure distributions are formed on the contact surfaces of the curvic couplings. The magnitude of contact stress difference value varies with the change of the blade-off position which shows smaller in position I than in position II and increment with the stage disc number increasing.

3. The torque load plays a critical role in bearing the power transmission, therefore the harmonious stress distribution is very important for the rotor to run stably and safely. However, from the analysis results in this paper, the uncoordinated contact pressure distribution has been found in the curvic couplings due to the torque load following a blade-off load which produces a unbalanced equivalent bending force. Thus the design in the gas turbine should ensure the curvic couplings have the capacity to hold the unbalanced load to avoid the happening of an unpredictable incidence.

4. The stiffness of the connection part of the rotor between the compressor end and the turbine end is a very important feature in consideration of the stress distribution of the curvic couplings under a blade-off load condition. An assessment of the effect of the thickness deciding the stiffness of that connection body part on the stress distribution of the curvic couplings is carried out. These analyses illustrate that the inclusion of a consideration in that thickness make a significant difference to the results at the curvic coupling stress. Hence, this feature mentioned above is worth being taken into account in the course of designing the gas turbine.

Acknowledgment. We would like to express our sincere thanks to the financial support of this work by the National Basic Research Program of China (Grant No. 2011CB706601).

\section{Резюме}

За допомогою тривимірної скінченноелементної моделі досліджено розподіл контактної напруги в криволінійних 'єднаннях високонавантаженої газової турбіни в умовах, що відповідають випадку відриву лопатки. Для різних положень лопаток, що відірвалися, на диску кожного ступеня контактна 
напруга у криволінійних з'єднаннях у випадку прикладення зусиль, що відповідають відриву лопатки, розподіляється по-різному. При цьому точка прикладення і величина зусилля, а також розподіл зусиль затягнення болтів кріплення суттєво впливають на розподіл контактних напруг. Окрім того, характер зміни контактних напруг як $з$ однієї, так і 3 іншої сторони "зуба" з’єднання при крутному моменті різний через зусилля, яке зумовлене відривом лопатки. До нормальної відцентрової сили додається неврівноважена згинальна сила. Показано, що жорсткість з'єднання частини ротора між торцями компресора і турбіни, що визначається жорсткістю його перерізу, має вплив на розподіл контактних напруг у криволінійних з'єднаннях. Проведено розрахунок жорсткості для кожного з таких з'єднань.

1. I. J. Richardson, T. M. Hyde, A. A. Becker, and J. W. Taylor, "A threedimensional finite element investigation of the bolt stresses in an aero-engine curvic coupling under a blade release condition," in: Proc. of the Institution of Mechanical Engineers, Part G: J. Aerospace Eng., 214, 231-245 (2000).

2. Y. Zeyong, H. Baian, W. Jianguo, et al., "Calculation of axial relaxed/pressed forces of rotors with curvic couplings," Acta Aeronaut. Astronaut. Sin., 5, Q16 (1996).

3. H. Baian, Y. Zeyong, and X. Youliang, "Determination of axial preloads of rotor with curvic couplings pretightened into two segments," J. Mech. Strength, 21, No. 4, 274-277 (1999).

4. N. L. Pedersen and P. Pedersen, "Stiffness analysis and improvement of bolt-plate contact assemblies," Mech. Based Des. Struct. Mach., 36, No. 1, 47-66 (2008).

5. S. R. Pisani and J. J. Rencis, "Investigating curvic coupling behaviour by utilizing the two and three dimensional boundary and finite element methods," in: Int. Conf. on Boundary Element Methods, XV: Fluid Flow and Computational Aspects (Aug. 10-13, 1993), pp. 597-608 (Computational Mechanics).

6. I. J. Richardson, T. H. Hyde, A. A. Becker, and J. W. Taylor, "A validation of the three-dimensional finite element contact method for use with curvic couplings by comparing predictions with photoelastic test data," in: Coupling and Shaft Technology for Aerospace Transmissions Seminar (June 9, 1999, Solihull) (Lucas Electrical and Electric Systems).

7. S.-X. Yuan, Y.-Y. Zhang, Y.-C. Zhang, and X.-J. Jiang, "Stress distribution and contact status analysis of a bolted rotor with curvic couplings," in: Proc. of the Institution of Mechanical Engineers, Part C: J. Mech. Eng. Sci., 224, 1815-1829 (2010).

8. ANSYS User's Manual Revision 8.0, ANSYS Inc., Canonsburg, PA (2004). 